\title{
Genetic counselling and family history in IBD: 30 years' experience at the Cleveland Clinic
}

\author{
WM MiCHENER, MD, M CAULFIELD, MD, RG FARMER, MD, R WyLliE, MD, K COTMAN, BS, J HERTZER
}

ABSTRACT: The Cleveland Clinic has followed 1288 patients with inflammatory bowel disease (IBD) (437 with mucosal ulcerative colitis and 851 with Crohn's disease) from 1955 through 1984. Of the 437 patients with mucosal ulcerative colitis, the index patient had one or more family members develop IBD. These data indicate the need for the treating physician to institute casefinding questions within the family so that early diagnoses can be established. From 1975 through 1984, 94 patients had a positive family history and 63 had additional family members with disease. The highest risk group was the siblingsibling group ( $6.4 \%$ in mucosal ulcerative colitis and $8.3 \%$ in Crohn's disease). Both groups had similar percentages for all immediate family members; namely, $16.5 \%$ and $17.3 \%$. In the group of patients reported from 1975 to 1984 , the location of disease in the index patient and the immediate family member was the same in $67.5 \%$ and different in $30.0 \%$. In this same group of patients, the disease similarity in the index patient and the immediate family member was the same in $86.8 \%$ and different in $12.0 \%$. These data suggest that while genetic factors undoubtedly increase the susceptibility for IBD, there is no specific genetic pattern identified. Also, environmental and other factors may be present. The data also suggest that the age of onset is a factor, perhaps showing increased association with a positive family history. Can J Gastroenterol 1990;4(7):350354 (pour résumé, voir page 351)

Key Words: Crohn's disease, Family history, Genetics, Ulcerative colitis

Division of Education, Cleveland Clinic Foundation, Pediatric and Adolescent Gastroenterology, Cleveland, Ohio, USA

Correspondence and reprints: Dr WM Michener, Chairman, Division of Education, Cleveland Clinic Foundation, Pediatric and Adolescent Gastroenterology, Cleveland Clinic Hospital, 9500 Euclid Avenue, Cleveland, OH 44106-4794, USA. Telephone (216) 444-2200, Fax (216) 444-0271
$\mathrm{D}$ URING THE PAST 30 YEARS, A large number of patients with the clinical features of Crohn's disease and ulcerative colitis with onset in child. hood or adolescence have been seen at the Cleveland Clinic (Table 1). A registry was established and periodic follow-up of these patients has been accomplished (1-3). In 1980, the initial report studied family history data in 838 patients with onset of inflam. matory bowel disease (IBD) younger than 21 years (4). Of 316 patients with ulcerative colitis, 93 (29\%) had positive family histories while 187 of 522 patients with Crohn's disease (35\%) had positive family histories for IBD. Fifteen per cent of immediate family members had IBD including $6 \%$ of siblings of patients with ulcerative colitis and $7.5 \%$ of siblings of patients with Crohn's disease. More than one family member was found to have IBD in 21 instances of ulcerative colitis $(6.6 \%)$ and 46 instances $(8.8 \%)$ with Crohn's disease.

In 1986, an update of follow-up data 


\section{Consultations génétiques et histoire familiale des MII: 30 ans d'expérience à la Cleveland Clinic}

RESUME: De 1955 à 1984, la Cleveland Clinic a suivi 1288 patients atteints de maladies inflammatoires de l'intestin (MII): 437 cas de colite ulcéreuse et 851 cas de maladie de Crohn. Parmi les 437 patients porteurs de colite ulcéreuse de la muqueuse, le probant avait un membre de sa famille ou plus, chez qui une MII s'était développée. D'après ces données, il serait nécessaire que le médecin traitant institue des questions destinées à révéler les antécédents familiaux afin d'accélérer le diagnostic. Entre 1975 et 1984, 94 patients avaient une histoire familiale positive et pour 63 patients, les MII se sont manifestées parmi d'autres membres de la famille. Le risque le plus élevé se trouvait dans les groupes de fratrie (6,4 \% pour la colite ulcéreuse et $8,3 \%$ pour la maladie de Crohn). Les deux groupes avaient des pourcentages similaires pour tous les membres immédiats de la famille soit $16,5 \%$ et $17,3 \%$. Dans le groupe de malades déclarés de 1975 à 1984, le site de la maladie chez le probant et le membre immédiat de la famille était le même dans 67,5\% des cas et différent dans 30,0\%. Dans ce même groupe de patients, la similarité de la maladie chez le probant et le membre immédiat de la famille était la même dans $86,8 \%$ des cas et différente dans $12,0 \%$. Ces données suggèrent que, s'il est certain que les facteurs génétiques augmentent la susceptibilité aux MII, aucune séquence génétique particulière n’a été identifiée. Des facteurs environnementaux et autres pourraient également intervenir. Il semble aussi que l'âge auquel la maladie se déclare soit un facteur, signalant peut-être une association accrue avec une histoire familiale positive.

\section{TABLE 1}

Cleveland Clinic experience with inflammatory bowel disease patients aged 20 years or younger (1955-84)

\begin{tabular}{lccc}
\hline Years & Ulcerative colitis $(\%)$ & Crohn's disease $(\%)$ & Total \\
\hline $1955-59$ & $69(65.7)$ & $36(34.3)$ & 105 \\
$1960-64$ & $69(45.7)$ & $82(54.3)$ & 151 \\
$1965-69$ & $86(30.7)$ & $194(69.3)$ & 280 \\
$1970-74$ & $92(30.4)$ & $210(69.6)$ & 302 \\
$1975-79$ & $44(21.6)$ & $157(78.4)$ & 201 \\
$1980-84$ & $77(30.0)$ & $172(70.0)$ & 249 \\
Total & 437 & 851 & 1288 \\
\hline
\end{tabular}

were published relating to family histories of the original study group (5). The mean follow-up for ulcerative colitis patients increased by six years and for Crohn's disease by nine years. This documented a $5 \%$ increase in the number of family members afflicted with IBD. The predominant family members afflicted continued to be siblings and first cousins (the horizontal pattern) rather than occurring from generation to generation. The association of a positive family history in over one-third of patients with onset of IBD in childhood points to the need for physician awareness in case-finding within families. This paper adds to the original study group data from new cases seen from January 1, 1974 through December 31, 1984. The observations in this group of patients are compared to the previously reported 1955-74 group, providing patient data for 30 years in some areas.

\section{PATIENTS AND METHODS}

As previously reported, the clinical, radiographic and histologic features, when available, were reviewed for each patient. Patients were classified as having Crohn's disease or ulcerative colitis according to established criteria $(1,3)$. All medical records were carefully reviewed and follow-up studies accomplished by techniques previously described. Trained observers contacted patients by telephone to obtain information pertaining to complications, family history data and clinical course of disease.

From January 1, 1975 through December 31, 1984, 450 additional patients with IBD were seen at the Cleveland Clinic and their data entered into the computer for study.

\section{RESULTS}

January 1, 1955 to December 31, 1974: The data concerning this group of patients have been published previously (4). Of note is that when a follow-up study was performed five years after the conclusion of the original study, 15 additional family members and relatives were diagnosed with ulcerative colitis to give a $34 \%$ prevalence (5). Five of these were immediate family members, an increase from 15.8 to $17.4 \%$. In Crohn's disease, 18 new family members and relatives were observed for an increase from 35 to $39 \%$. Seven of these were immediate family members, increasing the percentage from 16.6 to $18 \%$.

January 1, 1975 to December 31, 1984: Ulcerative colitis was observed in 121 patients and Crohn's disease in 329. Of the 450 patients with IBD, 94 $(20.9 \%)$ had a positive family history. Of these 94 patients, 63 were index patients (usually the first patient in the family who was seen at the Cleveland Clinic), 11 were other immediate family members, 16 had only extended family members with disease, one had an undetermined type of IBD, and three were lost to follow-up (Table 2). Of the 63 patients with an immediate family member with IBD, 16 had mucosal ulcerative colitis and 47 had Crohn's dis-

\section{TABLE 2}

\section{Breakdown of positive family history} patients

\begin{tabular}{lr}
\hline Index patients with immediate \\
family members \\
Lost to follow-up \\
Duplicates, ie, positive family \\
history patients who are immed- \\
iate family members of index \\
patients \\
Extended family only \\
Undetermined diagnosis \\
Patients with positive family \\
histories
\end{tabular}


TABLE 3

Family history data (1975-84)

\begin{tabular}{lcc}
\hline Disease & Frequency & $\%$ \\
\hline Mucosal & 16 & 25.4 \\
ulcerative colitis & & \\
Crohn's disease & 47 & 74.6 \\
Total & 63 & 100.0 \\
\hline
\end{tabular}

ease (Table 3 ). Table 4 shows the data concerning family relationships in patients with ulcerative colitis in the 30 year study. In the original study of 316 patients, 50 patients had a family history positive for the immediate family. Five years later in 1984, five patients were added to this number. In the third decade follow-up of the 121 patients with ulcerative colitis, 17 had a family history positive for the immediate family, giving a total of 72 of 437 patients $(16.5 \%)$. The highest percentage was in sibling relationships.

In Crohn's disease patients, of the 522 in the original study, 87 had a family history positive for the immediate family (Table 5). In 1984, further follow-up of that group added seven patients. In 1989,third decade followup added 53 more patients with a family history positive for the immediate family for a total of 147 of 851 patients observed in the 30 year period $(17.3 \%)$.

The percentage of patients with a family history positive for the immediate family has not changed significantly

TABLE 6

Family history data (1955-84)

\begin{tabular}{lc}
\hline Years & \\
\hline $1955-74$ & 137 of 838 patients $(16.3 \%)$ \\
$1955-74$ & $\begin{array}{c}149 \text { of } 838 \text { patients }(17.8 \%) \\
\text { (further follow-up) }\end{array}$ \\
$1975-84$ & 219 of 1288 patients $(17.0 \%)$ \\
\hline
\end{tabular}

Data from reference 4

TABLE 7

Intervals from diagnosis of index patients to diagnosis of immediate family members (years)

\begin{tabular}{lrrrrr}
\hline & $\mathbf{n}$ & Mean & SD & Median & P value \\
\hline Mucosal ulcerative colitis & 11 & 12.7 & 7.8 & 14.0 & 0.36 \\
$\quad$ Parent-child & 5 & 7.5 & 3.0 & 8.0 & \\
$\quad$ Sibling-sibling & & & & & \\
Crohn's disease & 24 & 10.8 & 8.0 & 7.8 & $0.001^{*}$ \\
$\quad$ Parent-child & 34 & 4.5 & 3.6 & 3.6 & \\
$\quad$ Sibling-sibling & &
\end{tabular}

Groups compared using Wilcoxon rank sum test. "Statistically significant. n Number of patients

TABLE 4

\section{TABLE 5}

"Statistically significant over 30 years of observation (Table 6) (5). In the original study of 838 patients, 137 had a positive family history $(16.3 \%)$. In the follow-up study of 1984 , the number increased to 149 of 838 patients $(17.8 \%)$. Current data with the addition of the third decade of patients, shows 219 of 1288 patients with a family history positive for the immediate family (17.0\%). These data show only the number of index patients with a sibling with IBD and do not reflect multiple siblings with disease.

The interval in years from the date of diagnosis compared to the date of diagnosis of an immediate family member was calculated for index patients in

Ulcerative colitis - Family relationships of 437 patients (1955-84)

\begin{tabular}{lcccr}
\hline & Original number & 1984 & 1989 & Total $(\%)$ \\
\hline Father-son & 4 & 1 & 3 & $8(1.8 \%)$ \\
Father-daughter & 8 & 0 & 1 & $9(2.1 \%)$ \\
Mother-son & 10 & 0 & 6 & $16(3.7 \%)$ \\
Mother-daughter & 9 & 0 & 2 & $11(2.5 \%)$ \\
Sibling-sibling & 19 & 4 & 5 & $28(6.4 \%)$ \\
Sister-sister & - & - & 1 & \\
Brother-brother & - & - & 2 & \\
Brother-sister & - & - & 2 & \\
Total & 50 & 5 & 17 & $72(16.5 \%)$ \\
\hline
\end{tabular}

Crohn's disease - Family relationships of 851 patients (1955-84)

\begin{tabular}{lcccc}
\hline & Original number & 1984 & 1989 & Total (\%) \\
\hline Father-son & 14 & 0 & 4 & $18(2.1 \%)$ \\
Father-daughter & 6 & 1 & 8 & $15(1.8 \%)$ \\
Mother-son & 14 & 1 & 7 & $22(2.6 \%)$ \\
Mother-daughter & 14 & 1 & 6 & $21(2.5 \%)$ \\
Sibling-sibling & 39 & - & $28^{\circ}$ & $71(8.3 \%)$ \\
Sister-sister & - & - & 8 & \\
Brother-brother & - & - & 10 & \\
Brother-sister & - & 7 & 53 & $147(17.3 \%)$ \\
Total & 87 & & & \\
\hline
\end{tabular}

the 1975-84 group (Table 7). In the index patients with ulcerative colitis, the mean age between the onset of dis. ease in the immediate family member was 11.1 years with a standard devia. tion of 7.0. In Crohn's disease, the mean age was 7.1 years and the stand. ard deviation 6.6. In Crohn's disease, there appeared to be a shorter interval between onset of disease in another sib. ling than between parent and child. The numbers of cases with ulcerative colitis were too small to allow analysis though a similar trend was recog. nizable.

The location of disease in the index patient and in the immediate family member was the same in $67.5 \%$ of cases and different in $30 \%$ (Table 8). In two cases, the location of disease in the immediate family member was unknown. Judgements regarding location of disease were made from all available infor. mation but could be in error in some cases as investigations were not always recent. Also, disease similarity (either ulcerative colitis or Crohn's disease) in the index patient and in the immediate family member was the same in $86.8 \%$ 
TABLE 8

Location of disease in index patient and immediate family member

\begin{tabular}{lccc} 
& Same & Different & Unknown \\
\hline Father-son & 4 & 0 & 1 \\
Father-daughter & 5 & 2 & 1 \\
Mother-son & 3 & 7 & \\
Mother-daughter & 5 & 2 & \\
Sibling-sibling & 37 & 13 & $2(2.5 \%)$ \\
Total & $54(67.5 \%)$ & $24(30.0 \%)$ & \\
\hline
\end{tabular}

\section{TABLE 9}

\section{Disease similarity in index patients and immediate family member}

\begin{tabular}{lccc}
\hline & Yes & No & Indeterminate \\
\hline Father-son & 4 & 2 & 1 \\
Father-daughter & 7 & 2 & \\
Mother-son & 11 & 3 & \\
Mother-daughter & 7 & 1 & \\
Sibling-sibling & 50 & 3 & $1(1.1 \%)$ \\
Total & $79(86,8 \%)$ & $11(12.1 \%)$ & \\
\hline
\end{tabular}

of cases and different in 12\% (Table 9). In one case, the disease in the immediate family member was undetermined.

Four sets of twins concordant for Crohn's disease were available for study (6). All eight patients presented during adolescence. The first patient had more sever disease as indicated by more relapses, hospitalizations and surgeries compared to the second twin. The clinical presentations were similar in each twin and the location of disease also similar. The time interval from time of presentation of symptoms to diagnosis was shorter in the second twin. Disease was usually not as advanced when therapy was started and this may have contributed to a more benign course. Tysk et al (7) have developed extensive data from the Swedish twin register concerning IBD in twins.

\section{WHAT SHOULD CLINICIANS} TELL PATIENTS AND FAMILIES

Studies at the Cleveland Clinic continue to document the occurrence of $\mathrm{IBD}$ in approximately one-third of the families of patients whose illness began in childhood or adolescence. The problems of long term follow-up studies have been detailed by Singer et al (8) and are very real. Increased patient and family awareness of these diseases has increased the accuracy of follow-up data. As shown by the authors' studies, as well as others, the predominance of disease in first degree relatives and decreased incidence in second degree relatives suggest multigene inheritance rather than single gene inheritance $(9$. 11). A basic genetic predisposition to the disease associated with an environmental triggering factor seems to be an understandable explanation for families (12).

In ulcerative colitis, $16.5 \%$ of index cases had another immediate family member with IBD. In Crohn's disease, $17.3 \%$ of cases had another immediate family member with disease. These data indicate the need for the treating physician to institute case-finding questions within the family so that early diagnosis can be established as needed. Early diagnosis with resulting early institution of therapy often leads to a less severe course for the subsequent members of a family with IBD. In Crohn's disease, the interval from date of diagnosis of index patients to the date of diagnosis of immediate siblings was usually under four years.

Twins, in particular, should be followed carefully for development of symptoms suggesting IBD so early recognition and therapy may occur (7).

The literature indicates that the frequency of marital IBD is extremely low (10). Hellers and Burnell (13) note that this is in favour of a genetic rather than environmental factor. They also note that the absence of disease in health care workers attending patients with IBD also supports the genetic rather than environmental etiology arguments.

Certainly, as many have suggested, there is a great need for genetic markers to help sort out the possible causes for IBD. The only accepted marker to date documents the association of ankylosing spondylitis and HLA B27 with these diseases (14).

The authors' data continue to suggest that while genetic factors may undoubtedly increase susceptibility, enviromental and other factors may also be present, and there is no specific genetic pattern identified that would indicate that family counselling with avoidance of childbearing should be suggested for patients with IBD.

These data also continue to suggest that age of onset is a factor perhaps showing increased association with a positive family history. Data from Stockholm and Chicago show similar results $(9,11,15)$.

\section{REFERENCES}

1. Farmer RG, Michener WM. Prognosis of Crohn's disease with onset in childhood or adolescence. Dig Dis Sci 1979;24:752-7.

2. Michener WM, Greenstreet RI, Farmer RG. Comparison of the clinical features of Crohn's disease and ulcerative colitis with onset in childhood or adolescence. Cleve Clin Q 1982;49:13-6.

3. Michener WM, Farmer RG, Mortimer EA. Long-term prognosis of ulcerative colitis with onset in childhood or adolescence. J Clin Gastroenterol 1979;1:301-5.

4. Farmer RG, Michener WM, Mortimer EA. Studies of family history among patients with inflammatory bowel disease. Clin Gastroenterol 1980;9:271-7.

5. Farmer RG, Michener WM. Association of inflammatory bowel disease in families. In: Rozen P, ed. The Genetics and Epidemiology of Inflammatory Bowel Disease. Basel: Karger, 1986: 17-24.

6. Steffen R, El-Youssef M, Wyllie R, Caulfield M, Michener W. Clinical manifestations of Crohn's disease in four pairs of concordant adolescent twins. Am J Gastroenterol 
1989;84:1197.

7. Tysk C, Londberg E, Jarnerot $G$, et al. Ulcerative colitis and Crohn's disease in an unselected population of monozygotic and dizygotic twins. Gut 1988;29:990-6.

8. Singer HC, Anderson JGD, Frischer H, et al. Familial aspects of inflammatory bowel disease. Gastroenterology 1971;61:423-30.

9. Lashner BA, Evans AA, Kirsner JB, et al. Prevalence and incidence of inflammatory bowel disease in family members. Gastroenterology 1986;91:1396-400.

10. Harries AD, Baird A, Rhodes J, Mayberry JF. Has the rising incidence of Crohn's disease reached a plateau? Br Med J 1982;284:235.

11. Monsen U, Broström O, Nordenvall B, et al. Prevalence of inflammatory bowel disease among relatives of patients with ulcerative colitis. Scand J Gastroenterol 1987;22:214-8.

12. Gilat T, Hacohen D, Lilos P, et al. Childhood factors in ulcerative colitis and Crohn's disease. An international cooperative study. Scand J

Gastroenterol 1987;22:1009-24.

13. Hellers G, Bernell O. Genetic aspects of inflammatory bowel disease. Med Clin North Am 1990;74:13-9.

14. Brewerton DA, Hart FD, Nicholls A, et al. Ankylosing spondylitis and HLA 27. Lancet $1973 ; \mathrm{i}: 904-7$.

15. Kirsner JB, Spencer JA. Family occurrences of ulcerative colitis, regional enteritis and ileocolitis. Ann Intern Med 1963;59:133. 


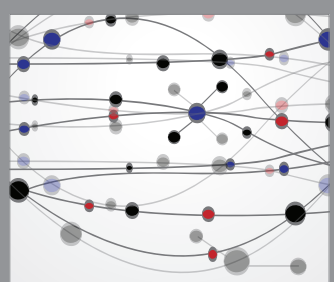

The Scientific World Journal
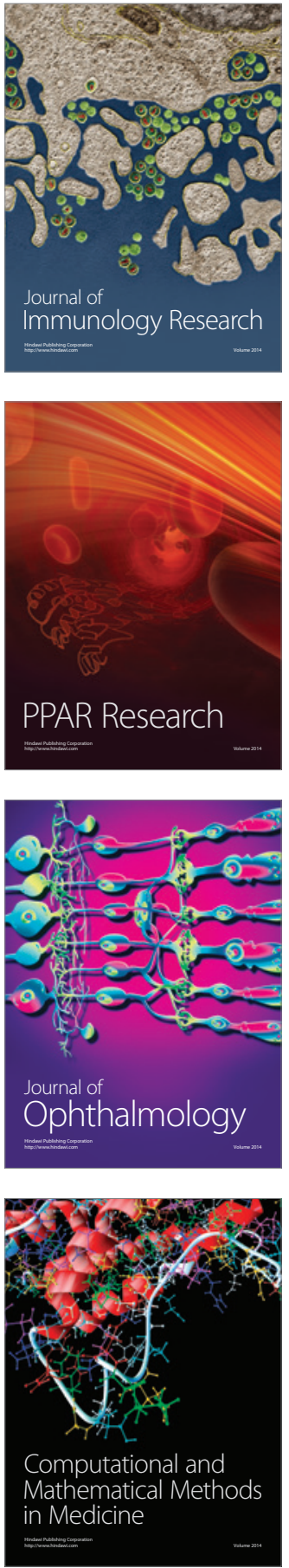

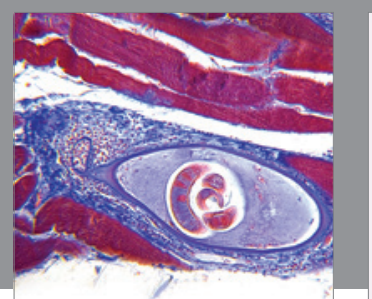

Gastroenterology Research and Practice

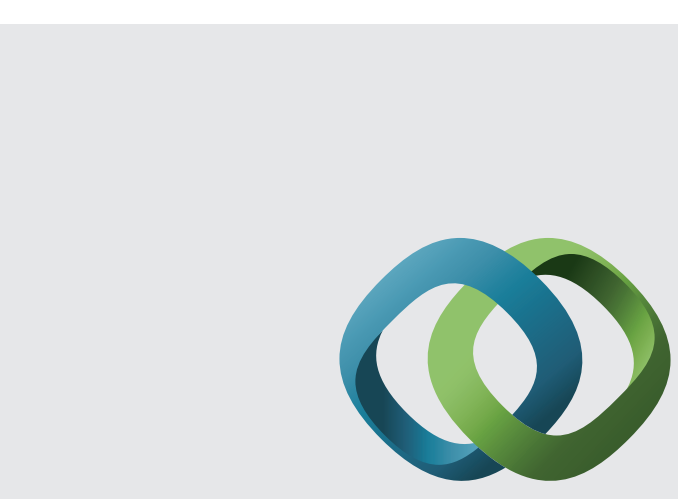

\section{Hindawi}

Submit your manuscripts at

http://www.hindawi.com
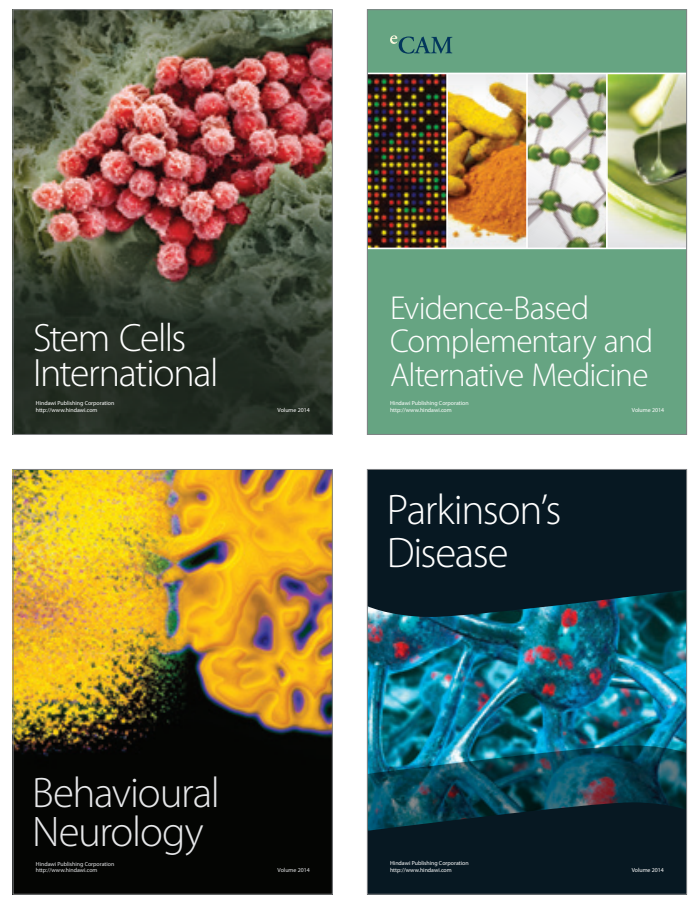
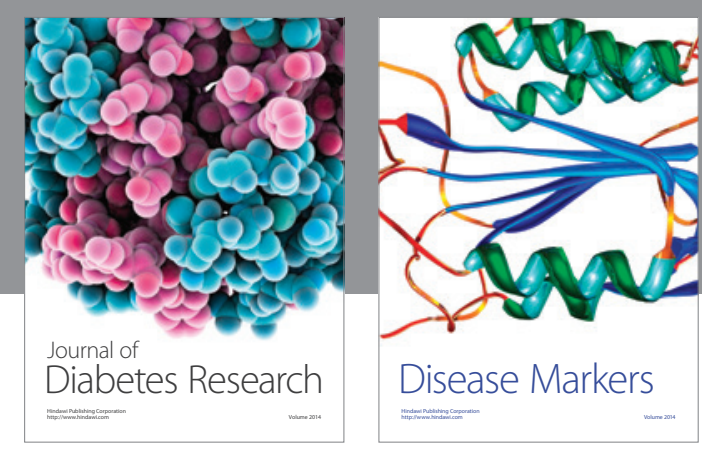

Disease Markers
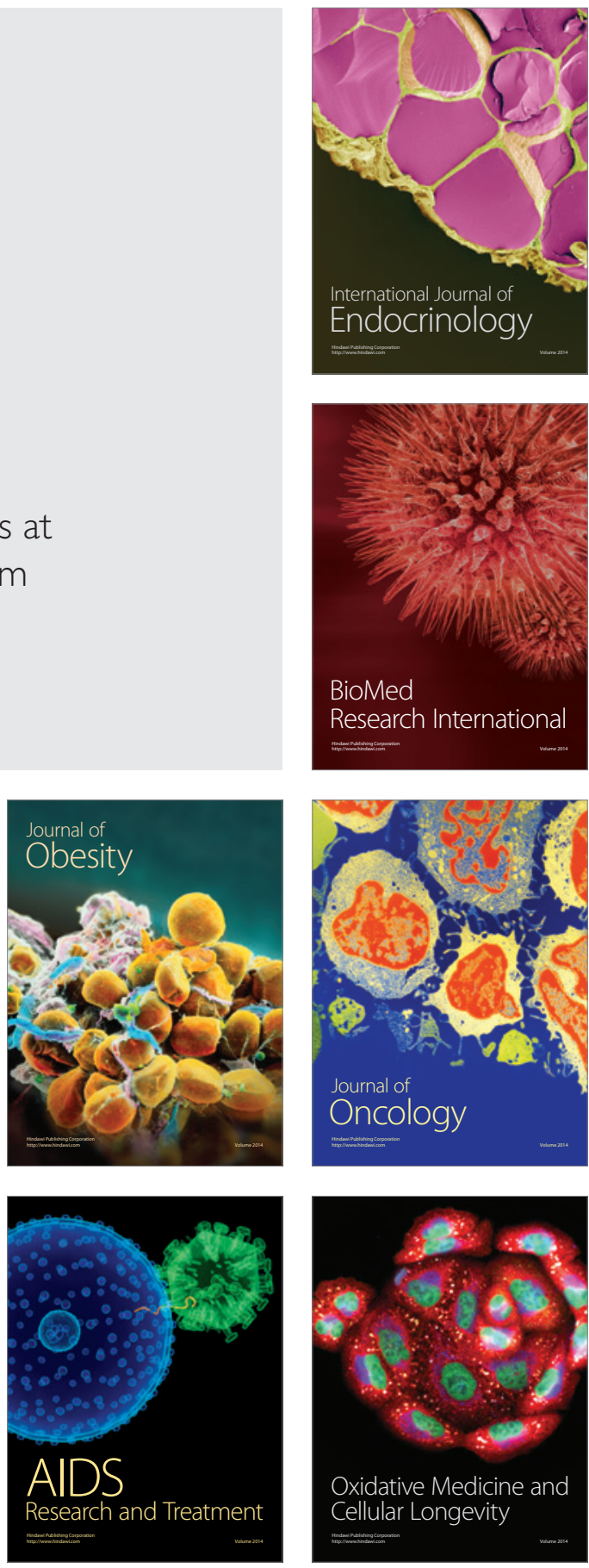